\title{
The rostral subcommissural ventral pallidum is a mix of ventral pallidal neurons and neurons from adjacent areas: an electrophysiological study
}

\author{
Yonatan M. Kupchik and Peter W. Kalivas \\ Department of Neurosciences, Medical University of South Carolina, Charleston, SC 29425, USA \\ Yonatan M. Kupchik: kupchik@musc.edu
}

\begin{abstract}
The ventral pallidum (VP) is a part of the ventral striatopallidal system and is involved in rewardrelated behaviors. The VP is composed of a ventromedial (VPvm) and a dorsolateral (VPdl) subregion, and some rostral-caudal differences are reported. Study of the VP often focuses on the subcommissural VP, typically considered homogenous in spite of known subdivisions. In this work, we used slice electrophysiology combined with immunohistochemistry for marker neuropeptides to test whether the subcommissural VP is functionally homogenous. Using sagittal slices, we show that more lateral levels $(2.40 \mathrm{~mm})$ of the subcommissural VP are homogenous but that a more medial slice $(1.90 \mathrm{~mm})$ contains two types of neurons. One type, located more caudally, resembles neurons in the lateral subcommissural VP, with long aspiny dendrites, primarily GABAergic input, and characteristic electrophysiological properties, such as depolarized membrane potential and spontaneous action potential discharge. The second type of neuron, located mostly in the rostral subcommissural VP, shows properties that are akin to medium spiny neurons of adjacent regions, including spiny dendrites, major glutamatergic input, hyperpolarized membrane potential, and no spontaneous action potentials. The two types of neurons were present in both the VPvm and VPdl, implying that the mix is not a characteristic of histologically defined subregions. We conclude that at medial levels the rostral subcommissural VP contains a mix of typical ventral pallidal neurons and spiny neurons similar to those in adjacent regions. This observation needs to be considered when interpreting past experiments and designing future experiments in the subcommissural VP.
\end{abstract}

\section{Keywords}

Ventral pallidum; Electrophysiology; Nucleus accumbens; Extended amygdala

\section{Introduction}

The ventral pallidum (VP), first described by Heimer and Wilson (1975), is a part of the ventral striatopallidal system and has been proposed to be a structure critical for translating motivation into motor output (Mogenson et al. 1980; Mogenson and Yang 1991). Supporting this contention, the VP is involved in the expression of motor behaviors (Napier 1993) and sensorimotor information processing (Forcelli et al. 2012; Kodsi and Swerdlow 1997), as well as plays a central role in reward-related behaviors, including addiction to drugs of abuse (Hiroi and White 1993; Root et al. 2012b; McFarland and Kalivas 2001;

(C) Springer-Verlag Berlin Heidelberg 2012

Correspondence to: Yonatan M. Kupchik, kupchik@musc. edu. 
Hubner and Koob 1990; Martin et al. 2008; Panagis et al. 1995; Root et al. 2010, 2012a; Skoubis and Maidment 2003; Smith et al. 2009; Tang et al. 2005; Wilson and Rolls 1990; Zarrindast et al. 2007).

The VP is composed of two primary populations of neurons. The majority of the neurons (about $80 \%$ ) (Gritti et al. 1993) are GABAergic neurons, which can be further divided into projection neurons and neurons that are proposed to be VP interneurons (Pang et al. 1998). The remaining are cholinergic neurons that are part of the magnocellular basal forebrain cholinergic system. The GABAergic cells have aspiny or sparsely spined dendrites that, in projection neurons, can be as long as $1 \mathrm{~mm}$ or more in rats (Bengtson and Osborne 2000; Pang et al. 1998). The soma size of these cells is bigger than that of the medium spiny neurons of the adjacent nucleus accumbens (O'Donnell and Grace 1993), but smaller than the VP cholinergic cells (Bengtson and Osborne 2000). Intracellular and extracellular recordings show that VP neurons, in contrast with nucleus accumbens cells, have a relatively depolarized membrane potential (about $-55 \mathrm{mV}$ ) (Lavin and Grace 1996), and show a variety of patterned spontaneous action potential discharge (Bengtson and Osborne 2000; Lavin and Grace 1996; Mitrovic and Napier 1995; Napier and Mitrovic 1999; Pang et al. 1998).

Anatomically, the VP is continuous with the more dorsal globus pallidus and borders with the nucleus accumbens rostrally, and ventrally and caudally with the substantia innominata and parts of the extended amygdala (Heimer et al. 1997a, b). The borders of the VP are defined on the basis of immunohistochemical staining for the peptides enkephalin and substance P (Haber and Nauta 1983; Switzer et al. 1982; Zahm and Heimer 1988). Based on its histochemical composition and connectivity, the VP is traditionally divided into two main subregions: the ventromedial VP (VPvm) and the dorsolateral VP (VPdl) (Tripathi et al. 2010; Zahm and Heimer 1988, 1990). The ventromedial VP is rich in neurotensin (Heimer et al. 1991; Churchill and Kalivas 1994; Zahm and Heimer 1988), innervated primarily by the nucleus accumbens shell sub-compartment (NAshell) (Heimer et al. 1991), and projects to the mediodorsal nucleus of the thalamus, the ventral tegmental area (VTA), and back to the NAshell (Churchill and Kalivas 1994; Groenewegen et al. 1993; Maurice et al. 1997; Zahm et al. 1996). The dorsolateral VP, on the other hand, lacks neurotensin (Heimer et al. 1991; Zahm and Heimer 1988), is innervated primarily by the nucleus accumbens core subcompartment (NAcore) (Heimer et al. 1991), and projects to the substantia nigra, the subthalamic nucleus, and back to the NAcore (Groenewegen et al. 1993; Bell et al. 1995; Zahm et al. 1996). In addition to the traditional histologically defined boundary, there is some evidence showing rostral-caudal differences in the VP. For example, the rostral VP projects to the NAshell, while the caudal VP projects to the NAcore (Churchill and Kalivas 1994). Also, Smith and Berridge (2005) showed that microinjection of opioids into the caudal VP increases reactivity to sucrose while it has the opposite effect when injected into the rostral VP. Finally, Root et al. (2012a) found that during cocaine self-administration in rats, rostral VP neurons show a firing pattern that is distinct from caudal VP neurons.

In spite of apparent rostral-caudal distinctions in the VP, the majority of electrophysiological and behavioral experiments involve the subcommissural part of the VP (i.e. the portion of the VP lying beneath the anterior or posterior limbs of the anterior commissure) without evaluating differences on the rostral-caudal axis (for example, Johnson and Napier 1996; Tang et al. 2005). Moreover, an in vitro characterization of VP cells in brain slices obtained from adult rats has not been conducted; although a few studies have been conducted in tissue obtained during the first week postpartum (Bengtson et al. 2004; Bengtson and Osborne 1999, 2000). In this study, we took an unbiased approach and systematically sampled neurons along the rostro-caudal axis of the VP without subdividing the VP into its known subregions. To determine if rostral-caudal distinctions may exist in VP neurons in 
accordance with the behavioral and anatomical studies in adult rat, we use the whole cell patch clamp technique to test whether GABAergic neurons in the subcommissural VP show different characteristics depending on their location along the rostral-caudal axis.

\section{Methods}

Animals

All experiments were conducted in accordance with the National Institute of Health Guidelines for the Care and Use of Laboratory Animals, and the Institutional Animal Care and Use Committee at the Medical University of South Carolina approved all procedures. Male Sprague-Dawley rats ( $250 \mathrm{~g}$ ) (Charles River Laboratories, Indianapolis, IN, USA) were single housed under controlled temperature and humidity with a 12-h light/dark cycle.

\section{Immunohistochemistry}

We used Met-Enkephalin antibody to define the borders of the VP as the VP was shown to contain high levels of enkephalin (Alheid and Heimer 1988; Gartner et al. 2002; Pickel et al. 2012; Tripathi et al. 2010). Although not the aim of this paper, a differentiation between the VPvm and VPdl was achieved by differences in enkephalin immuno-reactivity (Tripathi et al. 2010) and not by specific markers, such as neurotensin for the VPvm (Zahm and Heimer 1988). Rats were deeply anesthetized with a mixture of ketamine $\mathrm{HCl}(100 \mathrm{mg} / \mathrm{kg}$, Fort Dodge Animal Health, Fort Dodge, Iowa, USA) and xylazine ( $5 \mathrm{mg} / \mathrm{kg}$, Lloyd Laboratories, Shenandoah, Iowa, USA) and transcardially perfused with phosphate-buffered saline (PBS) containing $4 \%$ paraformaldehyde. Brains were post-fixed in PBS containing $4 \%$ paraformaldehyde overnight at room temperature. Sagittal sections $(100 \mu \mathrm{m})$ were washed in $0.3 \%$ hydrogen peroxide, washed three times in PBS and incubated in PBS containing $0.3 \%$ Triton-X (Sigma-Aldrich, Saint-Louis, MO, USA) (PBST) and $2 \%$ normal donkey serum. Slices were then incubated with Met-Enkephalin antibody (rabbit, 1:2000, Immunostar, Hudson, WI, USA) for $48 \mathrm{~h}$ at $4{ }^{\circ} \mathrm{C}$, washed and incubated with biotinylated secondary antibody (donkey anti-rabbit, $2 \mu \mathrm{l} / \mathrm{ml}$, Jackson Immunoresearch, West Grove, PA, USA). Following incubation, slices were incubated in PBST + ABC kit (Vecstatin Elite ABC peroxidase kit, Vector Laboratories, Burlingame, CA, USA) $(2 \mu \mathrm{l} / \mathrm{ml}$ each) for $90 \mathrm{~min}$ at room temperature. Finally, slices were transferred to Tris buffer containing diaminobenzidine (Sigma-Aldrich, Saint-Louis, MO, USA) $(0.2 \mathrm{mg} / \mathrm{ml})$ and hydrogen peroxide $(0.1 \mu \mathrm{l} / \mathrm{ml})$ for $\sim 7 \mathrm{~min}$. Slices were then quickly transferred to PBS to stop the reaction and mounted to visualize enkephalin expression under a light Nikon microscope.

Immunocytochemistry for GAD67 and neurobiotin was conducted on some tissue slices used in the electrophysiology experiments described below. Patched neurons were filled with $0.3 \%$ neurobiotin (Vector Laboratories, Burlingame, CA, USA), and $30 \mathrm{~min}$ after breaking the membrane of the cell the electrode was quickly pulled away and the slice was left in the chamber for 15 additional minutes to maximize neurobiotin diffusion. Slices were then fixed in PBS containing $4 \%$ paraformaldehyde for $1 \mathrm{~h}$, washed with PBST and incubated for $1 \mathrm{~h}$ (room temperature) in PBST containing Bovine Serum Albumin (BSA, Fisher Scientific, Fair Lawn, NJ, USA). Slices were then incubated with anti-GAD67 (mouse, 1:500, Millipore Corporation, Billerica, MA, USA) for $72 \mathrm{~h}$ at $4{ }^{\circ} \mathrm{C}$, washed and then incubated with the two secondary antibodies (streptavidin Alexa 488, 1:500, for neurobiotin; mouse Alexa 594, 1:500, for GAD67, Invitrogen Corporation, Carlsbad, CA, USA) for $2 \mathrm{~h}$ at room temperature. Slices were then mounted and the neurobiotin and/or GAD67 labeling visualized under a Leica confocal microscope (Leica TCS SP5 MP, Leica Microsystems GmbH, Wetzlar, Germany). Alexa 488 (labeling neurobiotin) was excited with an Argon $543 \mathrm{~nm}$ laser and the Alexa 594 (labeling GAD67) was excited with a Helium/Neon laser. Images were scanned along the $z$ axis at $0.5 \mu \mathrm{m}$ intervals with a frame 
size of $1,024 \times 1,024$ pixels. $Z$ stacks were collapsed to one plain for presentation in the manuscript.

\section{Slice preparation and electrophysiological recordings}

Rats were anesthetized with ketamine $\mathrm{HCl}(100 \mathrm{mg} / \mathrm{kg})$ and decapitated. The brain was removed and sagittal slices $(220 \mu \mathrm{m})$ were prepared (VT1200S Leica vibratome, Leica Microsystems, Wetzlar, Germany) and collected into a vial containing aCSF (in mM: 126 sodium chloride, 1.4 sodium phosphate, 25 sodium bicarbonate, 11 glucose, 1.2 magnesium chloride, 2.4 calcium chloride, 2.5 potassium chloride, 2.0 sodium pyruvate, 0.4 ascorbic acid, bubbled with $95 \%$ oxygen and $5 \%$ carbon dioxide) and a mixture of $5 \mathrm{mM}$ kynurenic acid and $100 \mu \mathrm{M}$ MK-801 maleate. Slices were stored at room temperature until used. All recordings were made at $32{ }^{\circ} \mathrm{C}$ (TC-344B, Warner Instrument Corporation). Neurons were visualized with an Olympus BX51WI microscope. Multiclamp 700B (Axon Instruments, Union City, CA, USA) was used to record postsynaptic currents (PSCs) under $-80 \mathrm{mV}$ voltage clamp whole cell configuration. Glass microelectrodes (1-2 M $\Omega$ ) were filled with internal solution (in mM: 68 potassium chloride, $65 \mathrm{D}$-gluconic acid potassium salt, 7.5 HEPES potassium, 1 EGTA, $1.25 \mathrm{MgCl}_{2}, 10 \mathrm{NaCl}, 2.0 \mathrm{MgATP}$, and $0.4 \mathrm{NaGTP}, \mathrm{pH} 7.2$ $7.3,275 \mathrm{mOsm})$. Cholinergic cells, which comprise the minority of the cells in the VP (Gritti et al. 1993), were avoided by virtue of their bigger soma and more hyperpolarized membrane potential (Bengtson and Osborne 2000) (although we cannot completely rule out occasional recording from a cholinergic neuron as we did not check for lack of immunoreactivity for the acetylcholine synthetic enzyme choline acetyltransferase in the recorded neurons). For histochemistry experiments, $0.3 \%$ neurobiotin was added to the internal solution (see above). Data were acquired at $10 \mathrm{kHz}$, and filtered at $2 \mathrm{kHz}$ using Axo-Graph X software (AxoGraph Scientific, Sydney). To evoke PSCs, a bipolar stimulating electrode was placed $\sim 200-300 \mu \mathrm{m}$ rostral of the recorded cell. The stimulation intensity that was chosen evoked a $\sim 50 \%$ of maximal PSC. For mapping the VP (Fig. 1), each slice was fully photographed (CCD-IR XC-EI50 video camera module, Sony Corporation, Japan), as was the electrode patching a cell, allowing for offline superimposition of the electrode image on the slice for exact location in the VP. Membrane potential, membrane capacitance, action potentials, and input resistance were collected for $30 \mathrm{~s}$ immediately after invading the cell to avoid changes produced by the internal solution. Otherwise, recording of spontaneous or evoked PSC started no earlier than 10 min after invading the neuron to allow diffusion of the internal solution to remote dendrites. Membrane capacitance and input resistance were calculated automatically from a $2 \mathrm{mV}$ pulse by the acquisition program Axograph X. Membrane capacitance was used to calculate the cell's membrane surface area using Eq. 1:

$$
4 \pi a^{2}=\frac{c_{\mathrm{in}}}{c_{\mathrm{m}}}
$$

where $4 \pi a^{2}$ is the cell's membrane surface area (in $\left.\mathrm{cm}^{2}\right), C_{\text {in }}$ is the membrane capacitance (in $\mathrm{pF}$ ), and $C_{\mathrm{m}}$ is the specific membrane capacitance which equals in most biological membranes to $1 \mathrm{pF} / \mathrm{cm}^{2}$. Using the membrane surface area, we could calculate the specific membrane resistance for each cell using Eq. 2:

$$
R_{\mathrm{m}}=R_{\mathrm{in}} \times 4 \pi a^{2}
$$

where $R_{\mathrm{m}}$ is the cell's specific membrane resistance (in $\Omega \mathrm{cm}^{2}$ ) and $R_{\text {in }}$ is the input resistance of the cell (in $\Omega$ ) (Koester and Siegelbaum 2000).

Recordings were collected every $20 \mathrm{~s}$ and averaged over $1 \mathrm{~min}$. Series resistance $\left(R_{\mathrm{S}}\right)$ measured with a $2 \mathrm{mV}$ depolarizing step $(10 \mathrm{~ms})$ given with each stimulus and holding 
current were always monitored online. Recordings with unstable $R_{\mathrm{S}}$, or when $R_{\mathrm{S}}$ exceeded $20 \mathrm{M} \Omega$, were aborted.

\section{Statistics}

Significance was tested using one- or two-way ANOVA with Bonferroni post hoc analysis for multiple comparisons between groups.

\section{Results}

\section{Passive electrophysiological measures of VP cells}

To study the characteristics of the subcommissural VP cells along the rostral-caudal axis, we used sagittal slices from adult rat brains. Enkephalin immunoreactivity was used to provide neurochemical delineation of the VP (Tripathi et al. 2010; Zahm et al. 1985; Gartner et al. 2002; Pickel et al. 2012) at mediolateral levels $1.90 \mathrm{~mm}$ (here referred to as "medial slice") and $2.40 \mathrm{~mm}$ (referred to as "lateral slice") (Fig. 1 $\mathrm{a}_{1,2}$ ). The rostral borders of the VP were clearly delineated by enkephalin staining. The caudal borders were less distinct and in determining them we consulted previous works (Paxinos and Watson 2006; Tripathi et al. 2010). To characterize the electrophysiological properties of the neurons in the VP, we used fresh brain slices at the same mediolateral levels as those shown in Fig. 1a. Using the whole cell patch clamp technique, we patched cells in the VP and obtained several measures shortly after the cell was invaded: membrane potential, membrane capacitance (which is representative of the amount of cellular plasma membrane), input resistance, specific membrane resistance (which reflects the membrane composition), and spontaneous action potential frequency. To describe differences in the cell types along a rostral-caudal axis, we divided all neurons into two groups in each mediolateral plane. The discriminating value for each measurement was chosen to be the median values of all cells recorded in the medial slice of the VP, since the VP in the medial slice showed more heterogeneity than the VP in the lateral slice.

Since this work is, to our knowledge, the first to systematically explore the electrophysiological characteristics of VP neurons, we took an unbiased approach and did not initially divide the cells into the known dorsolateral (VPdl) and ventromedial (VPvm) subregions of the VP. Examining the electrophysiological values of subcommissural VP neurons in the medial slice revealed two types of neurons (Fig. $1 b_{1}, c_{1}, d_{1}, e_{1}, f_{1}$ ). One type resembled previously reported neurons in the VP (Lavin and Grace 1996; Pang et al. 1998) and was located mostly in the caudal part of the VP (these cells are termed here "type 1" neurons). The other type of neuron showed different properties and was located largely in the rostral part of the VP (these cells are termed here "type 2" neurons). The rostral-caudal distinction is evident from maps prepared according to each of the measures of the neuron's passive electrical properties. Cells with a hyperpolarized membrane potential $(<-60 \mathrm{mV})$ were located more rostrally, while cells with a depolarized membrane potential $(>-60 \mathrm{mV})$ were located primarily in the caudal part of the VP $\left(\right.$ Fig. $\left.1 b_{1}\right)$. Likewise, cells with low input resistance $(<180 \mathrm{M} \Omega)$ and low specific membrane resistance (i.e. the resistance of the membrane per unit area, reflecting the density of channels in the membrane; $<3,000 \Omega \mathrm{cm}^{2}$ ) were mostly in the rostral VP, while cells with higher input resistance $(>180 \mathrm{M} \Omega$ ) and higher specific membrane resistance $\left(>3,000 \Omega \mathrm{cm}^{2}\right)$ were caudal (Fig. $\left.1 \mathrm{c}_{1}, \mathrm{~d}_{1}\right)$. In addition, cells with low spontaneous firing rate of action potentials $(<0.01 \mathrm{~Hz})$ were located rostrally while cells with higher firing rates were located in the caudal VP (Fig. 1e $\mathrm{e}_{1}$ ). Finally, most of the cells that showed higher membrane capacitance $(>14.5 \mathrm{pF})$ were rostral, while cells with low membrane capacitance tended to be caudal (Fig. $1 \mathrm{f}_{1}$ ). In contrast to the medial slice, the subcommissural VP in the lateral slice (Fig. $1 b_{2}, c_{2}, d_{2}, e_{2}, f_{2}$ ) was more homogenous, containing mostly type 1 cells exhibiting values akin to neurons of the caudal VP in the 
medial slice. It should be noted that although the caudal parts of the subcommissural VP look homogenous electrophysiologically, there is a possibility that they also contain a mix of pallidal and other neurons, since it has been shown that parts of the central extended amygdala bordering the caudal-medial VP contain pallidal-like neurons (Alheid 2003).

When dividing the VP (in both mediolateral planes) into rostral and caudal regions (Bregma $0.0 \mathrm{~mm}$ being the border), we found that on average the cells in the rostral VP of the medial slice, the majority of which are type 2 neurons, were different from the rest of the VP cells (i.e. type 1 neurons in the caudal VP of the medial slice and all lateral VP) in all measurements (Fig. 2a-e). For example, type 1 neurons in the caudal VP of the medial slice and in the lateral slice had on average a more depolarized membrane potential [comparable to that found in previous work (Bengtson and Osborne 2000; Lavin and Grace 1996)] and higher input resistance than type 2 neurons in the rostral VP of the medial slice (Fig. 2a, b). Since the input resistance of a neuron depends on the membrane surface area of the neuron and the specific membrane resistance (Koester and Siegelbaum 2000), the differences in input resistance could reflect differences in either of these parameters. Indeed, we found that the specific membrane resistance of type 2 neurons was lower (i.e. higher channel density) than that of type 1 neurons (Fig. 2c), and that type 2 neurons had higher membrane capacitance than all other VP cells (Fig. 2d). Also, type 1 neurons showed significant spontaneous firing of action potentials (Bengtson and Osborne 2000; Lavin and Grace 1996), while most of the type 2 neurons did not fire at all (Fig. 2e). Interestingly, the measures of the type 2 VP neurons were similar to those obtained from nucleus accumbens cells (leftmost bars in Fig. 2a-e).

In addition to dividing the neurons based on their own properties, we also divided them into the known VP subregions, VPvm and VPdl. In determining the borders between the VPvm and VPdl, we relied on the fact that enkephalin staining is denser in the VPdl (Tripathi et al. 2010). Also, we consulted previous work that used similar sagittal planes as we use here (Tripathi et al. 2010; Paxinos and Watson 2006). In the lateral slice, we found no difference between the VPdl and VPvm in the electrophysiological properties of the neurons (Table 1), as both subregions consisted mainly of type 1 neurons. In the medial slice, we found that the VPdl (positioned at the rostrodorsal end of the VP) consisted mainly of type 2 neurons, while the VPvm contained a mix of type 1 and type 2 neurons. Within the VPvm, the type 2 neurons were restricted to the rostral portion while the caudal part of the VPvm consisted of type 1 neurons. Thus, the electrophysiological properties of VPdl neurons in the medial slice were different than those in the caudal part of the VPvm, but not from those in the rostral part of the VPvm (Table 1). If comparing the VPdl in the medial slice to the entire VPvm in the medial slice, differences can be found in all measurements (data not shown). However, the type 2 cells that predominate in the VPdl, also predominate ventral to the VPdl in the rostral VPvm of the medial slice, indicating that the classic histological demarcation of the VP is not capturing the different locations of the type 1 and type 2 neurons in the VP.

Supporting the different distributions of neurons between the medial and lateral slices, we found that while three of the measurements (i.e. membrane potential, capacitance, and input resistance, randomly selected) do not correlate with each other in the lateral slice (Fig. 3d-f), in the medial slice the membrane potential was negatively correlated with capacitance and positively correlated with input resistance, and membrane capacitance was negatively correlated with input resistance (Fig. 3a-c). This shows that generally cells having "type 2" values for one property (i.e. low input resistance) also have "type 2" values for the other two measurements.

Next, we examined whether there is a clear border between type 1 and type 2 neurons in the more medial slice of the VP or a gradual transition between the two types of neurons. For 
this analysis, we binned the maps from Fig. 1 (for membrane potential and membrane capacitance) into $0.1 \mathrm{~mm}$ columns and calculated the average membrane potential and capacitance for each column. As can be seen in Fig. 4, the transition from type 2 neurons to type 1 neurons is gradual. Since we did not find in our measurements another type of cell other than the type 1 and type 2 neurons described above, the intermediate averages seen in the rostral part of the subcommissural VP reflect a mixture of type 1 and type 2 neurons. This is supported by the higher variance in the intermediate points compared to the variance in the accumbens or the caudal VP. The average coefficient of variation was $19.5 \pm 3 \%$ (rostral) and $11.1 \pm 1.4 \%$ (caudal) for membrane potential $(p<0.05)$ and $27.5 \pm 1.3 \%$ (rostral) and $19.2 \pm 0.9 \%$ (caudal) for capacitance ( $p<0.01$ ). In the intermediate points, we did not find that type 1 or type 2 neurons were restricted to the VPvm or VPdl (Table 1). Thus, the high variance in the intermediate points cannot be explained by the inclusion of the two subregions in the same bin.

\section{Rostral and caudal VP neurons in the medial slice are morphologically different}

To examine the morphology of the cells in the VP, we patched cells with an electrode containing neurobiotin. Figure 5 shows representative images of the two neuron types in the medial slice and the lateral slice, revealing that the type 1 and type 2 neurons in the medial slice show morphological differences (Fig. 5a $\mathrm{a}_{2}, \mathrm{~b}_{2}$ ). The representative type 2 neuron reveals spiny dendrites that are relatively short $(200-300 \mu \mathrm{m})$; a morphology that is similar to medium spiny neurons in the nucleus accumbens (O'Donnell and Grace 1993) and to the adjacent parts of the extended amygdala (Alheid and Heimer 1988). In contrast, the type 1 neuron has long, aspiny, dendrites that are more than $1 \mathrm{~mm}$ long. These cells resemble type I VP neurons from Pang et al. (1998) and type II globus pallidus neurons of guinea pig from Nambu and Llinas (1997). Similar to the electrophysiological measurements, the type 1 VP neuron in the lateral slice is morphologically akin to the type 1 caudal neuron in the medial slice (Fig. 5c). Note that in spite of having much shorter dendrites, the type 2 VP neurons exhibit a higher membrane capacitance, presumably a result of the large number of spines. When examining the presence of the two morphological cell types in VP subregions we found that neither type was restricted to the VPdl or VPvm of the medial slice (i.e. spiny type 2 neurons and aspiny type 1 neurons were found in the VPdl and VPvm of the medial slice). All cells showed immunoreactivity to GAD67, indicating that they are GABAergic neurons (cholinergic cells were avoided, see "Methods").

\section{The rostral and caudal VP neurons in the medial slice receive different synaptic input}

While the caudal cells in the medial slice show similar characteristics to those in the lateral slice, and previously characterized VP cells (Bengtson and Osborne 2000; Heimer et al. 1997b; Pang et al. 1998), type 2 neurons in the medial slice show properties that are indistinguishable from those of nucleus accumbens (O’Donnell and Grace 1993) or extended amygdala (Alheid and Heimer 1988) medium spiny neurons. In addition, it has been shown that neurons from different subregions in the VP (ventromedial vs. dorsolateral VP) exhibit different density of synaptic input (Zahm 1989). This raises the possibility that although the rostral part of the VP in the medial slice shows immunoreactivity to enkephalin, the cells in that region may resemble adjacent regions not only in their morphology and electrophysiology, but also in the information they receive from other brain regions. To test this, we compared the synaptic inputs between the two types of VP neurons, since it is known that the primary input to the accumbens and the extended amygdala is glutamatergic (Fuller et al. 1987; Yin and Knowlton 2006; Kelley et al. 1982) and the input to the VP originates largely from GABAergic neurons in the nucleus accumbens (Churchill and Kalivas 1994; Groenewegen et al. 1990; Heimer et al. 1991). We measured the effects of 6cyano-7-nitroquinoxaline-2,3-dione (CNQX) $(10 \mu \mathrm{M})$, an AMPA/kainate glutamate receptor blocker, and picrotoxin $(50 \mu \mathrm{M})$, a noncompetitive $\mathrm{GABA}_{\mathrm{A}}$ receptor antagonist, on the 
amplitude of evoked postsynaptic currents (ePSCs) and on the amplitude and frequency of spontaneous postsynaptic currents (sPSCs). Figure 6 shows that akin to the passive electrophysiological properties, type 2 neurons differed from type 1 neurons. CNQX inhibited the amplitude of ePSCs in type 2 neurons, but was largely without effect on the rest of the VP neurons (Fig. 6a, representative traces in Fig. 6d-f). Picrotoxin elicited opposite results, inhibiting ePSCs in type 1 neurons, but not in type 2 neurons.

The same distinction in predominant afferent input was true for the amplitude and frequency of sPSCs (Fig. 6b-c). Following CNQX treatment, the amplitude of the sPSCs was increased only in type 2 neurons. The paradoxical increase in sPSCs amplitude after blocking AMPA receptors is probably because we employed a high chloride internal electrode solution. The high-chloride internal produces large $\mathrm{GABA}_{\mathrm{A}}$-mediated chloride currents, and by blocking the smaller glutamate-dependent sodium currents the average amplitude was increased. Also note that treatment with CNQX did not decrease the sPSCs frequency in type $1 \mathrm{VP}$ neurons. This is because some cells showed a reduction in the sPSC frequency but in others the frequency of the GABAergic sPSCs was increased after CNQX. In contrast to the effect of CNQX, picrotoxin decreased the amplitude and frequency of sPSCs in type $1 \mathrm{VP}$ neurons (note that picrotoxin decreased sPSC frequency in type 2 neurons as well, indicating some spontaneously active GABAergic input to those cells). Importantly, co-application of both antagonists completely blocked ePSCs and sPSCs in all regions and cell types, implying that the majority of ionotropic input to VP neurons is glutamatergic and GABAergic.

\section{Discussion}

The VP has been described mainly using histochemical methods, while electrophysiological characterization of VP cells is sparse. Here, we used both histochemical and electrophysiological tools to characterize the subcommissural VP over its rostral-caudal axis, and showed that in more medial slices of the VP the histochemical and the electrophysiological maps do not completely overlap. The most rostral part of the VP as defined by enkephalin immunoreactivity contains a few cells similar to previously reported VP cells (Lavin and Grace 1996; Pang et al. 1998) (type 1 neurons), but is largely composed of cells that show very different electrophysiological characteristics (type 2 neurons). Thus, the rostral subcommissural VP contains a mix of typical VP neurons and other neurons that differ in their morphology and electrophysiology from typical VP neurons and resemble spiny neurons found in the adjacent nucleus accumbens and extended amygdala. In contrast, the rest of the subcommissural VP is homogenously composed mostly of type 1 neurons and exhibits typical VP characteristics. The border between type 2 and type 1 rich areas in the medial slice of the VP did not overlap with the border between the known subregions of the VP, the VPvm and VPdl. While the VPdl in the medial slice was largely composed of type 2 neurons, the VPvm contained both cell types, with type 2 predominant in the rostral and type 1 most common in the caudal VPvm. The finding of a mixed area in the rostral subcommissural VP that is distinct from the rest of the VP is supported by several lines of evidence and, as discussed below, affects the interpretation of already published work and the design of future work.

\section{Is the rostral subcommissural VP a part of the VP?}

In contrast with the rest of the VP, the rostral subcommissural VP in the medial slice used here $(1.90 \mathrm{~mm}$ lateral $)$ contains a heterogenous population of neurons. One subtype of neuron (type 1) resembles neurons in the rest of the VP, but a second subtype (type 2) shows different passive and stimulated electrophysiological characteristics. While both cell types could functionally belong to the same parent region (the VP), it is possible that this mix reflects a "leakage" of cells from an adjacent region into the VP. Although type 2 neurons 
are located in the enkephalin-rich VPdl subregion and the rostral VPvm, they appear to be more similar to neurons in the NAshell, which lies on the rostral border of the VP (Heimer et al. 1997b; Tripathi et al. 2010). The NAshell is composed mostly of medium spiny neurons (Alheid and Heimer 1988; O'Donnell and Grace 1993) that show remarkably similar characteristics to type 2 neurons. Type 2 neurons and NAshell cells have spiny dendrites of medium length $(\sim 200 \mu \mathrm{m})$. Also, both types of cells show similar passive electrophysiological properties, including a hyperpolarized membrane potential ( -70 to -80 $\mathrm{mV}$ ) and relatively low ( $<180 \mathrm{M} \Omega$ ) input resistance. Lastly, similar to NAshell neurons (Fuller et al. 1987; Yin and Knowlton 2006) the major input to type 2 neurons is glutamatergic, and not GABAergic, as it is in the rest of the VP (Churchill and Kalivas 1994; Groenewegen et al. 1990; Heimer et al. 1991).

In addition, the type 2 neurons could also belong to the extended amygdala (Alheid 2003). On its rostrodorsal edge, the subcommissural medial part of the VP borders with the interstitial nucleus of the posterior limb of the anterior commissure (IPAC). This area, which belongs to the lateral part of the central extended amygdala (Shammah-Lagnado et al. 1999, 2001), contains cells that are indistinguishable from NAshell neurons, both morphologically and in terms of connectivity (Alheid and Heimer 1988; Shammah-Lagnado et al. 1999).

Interestingly, the convergence of the rostral subcommissural VP with the caudomedial NAshell and the extended amygdala has been regarded as an amygdalostriatal transition zone that contains a mixture of striatal and amygdaloid cells. Heimer et al. (1997b) wrote that this area shows an "apparent mixture... between ventral pallidal and extended amygdaloid elements underneath the posterior limb of the anterior commissure". Based on histochemical resemblance, the extended amygdala includes the caudomedial NAshell (Alheid 2003). If that is indeed the case then the spiny cells we found in the medial slice of the rostral subcommissural VP might be functionally part of the extended amygdala. However, the caudomedial NAshell and the extended amygdala have been suggested by Zahm (1998) to be two different structures, indicating that further functional and anatomical delineation may be necessary to determine exactly how to classify the neurons at the more medial levels of the rostral subcommissural VP.

\section{Implications for past and future studies}

Anatomy studies in the basal forebrain have shown that in spite of clear staining differences between the VP and adjacent regions (Alheid and Heimer 1988; Tripathi et al. 2010; Zahm and Heimer 1988), the boundaries between the VP and adjacent regions are less definitive (Alheid 2003; Heimer et al. 1997b) and mixtures of cells types around the borders of the VP exist. These studies used histochemical and morphological features and did not supply evidence that the morphologically different neurons also differ in their electrophysiological properties or in the input they receive. The present work shows for the first time that at the more medial levels of the subcommissural VP the rostral pole contains some typical VP neurons and is largely composed of other neurons (potentially NAshell or extended amygdala spiny neurons) that differ in their electrophysiological properties and their synaptic input patterns. This should be taken into account when interpreting or designing behavioral and electrophysiological experiments in the VP. Although the majority of the studies in the VP to date have been largely restricted to the more caudal VP (for example, Kalivas et al. 2001; Robledo and Koob 1993; Taha et al. 2009; Tindell et al. 2006), there are also a number of studies showing differences between the rostral and caudal VP (Cromwell and Berridge 1993; Root et al. 2012a; Smith and Berridge 2005; see review by Smith et al. 2009). A summary of the work describing rostral-caudal differences in the VP (Smith et al. 2009) shows that the caudal VP contains a "hedonic" spot, in which injection of a $\mu$ opioid receptor agonist increases hedonic reactivity to sucrose (Smith and Berridge 2005; Tindell et al. 2006; although see Zahm et al. 2012 who suggest this hedonic spot to involve the lateral 
preoptic area or a transition zone between the caudal VP and the lateral preoptic area rather than the VP alone). In contrast, injection of the $\mu$ opioid receptor agonist to the rostral VP suppresses hedonic reactivity (Smith and Berridge 2005). In addition, it was found that during cocaine self-administration VP cells show various firing activity patterns. After pressing a lever to self-administer cocaine, the majority of cells show a change in activity followed by reversal of the activity that was completed only before the following press (termed "progressive reversal"). These cells were located mainly in the caudal part of the VP. In contrast, most of the cells in the rostral VP exhibited "early reversal"- the reversal of the activity change was completed shortly after pressing the lever (Root et al. 2012a). These rostral-caudal differences could be caused by a different distribution of the $\mu$ opioid receptor (Olive et al. 1997), different levels of enkephalin (Holt and Newman 2004; Maidment et al. 1989), a different ratio between cholinergic and non-cholinergic cells (Bengtson and Osborne 2000), and/or different connectivity with the nucleus accumbens (Churchill and Kalivas 1994).

Importantly, the present study raises the possibility that measurements from or manipulations of the rostral VP likely include neurons that might belong functionally to other regions. For example, using the coordinates in the present study for dividing the rostral from caudal VP in the medial slice (Bregma 0.0), the rostro-caudal division in the hedonic responsiveness to microinjection of $\mu$ opioid receptor agonist could correspond to the effects of stimulating $\mu$ receptors on type 1 versus type 2 neurons (e.g. see Fig. $6 \mathrm{~b}$ of Smith and Berridge 2005). However, the anhedonic spot may not include nucleus accumbens-like cells since activation of $\mu$ opioid receptors in the nucleus accumbens proper leads to increased feeding behavior (Hanlon et al. 2004; Pecina and Berridge 2005; Taha et al. 2009; Zhang and Kelley 1997, 2000). Unfortunately, few experiments have been conducted in the IPAC where neurons appear to resemble the rostral VP, and it is unknown if stimulation of $\mu$ opioid receptors in IPAC cells leads to a decrease in feeding behavior akin to the rostral VP. Also potentially supporting a potential role for accumbens-like type 1 neurons in studies showing rostro-caudal behavioral differences, the more medial part of the nucleus accumbens shell contains cells exhibiting "early reversal" patterns following selfadministration of cocaine (Fabbricatore et al. 2010) similar to rostral VP cells (Root et al. 2012a). Clearly future studies need to be designed that specifically test the involvement of the rostro-medial type 2 cell group in the VP in these and other rostro-caudal behavioral distinctions.

In conclusion, we present here the first systematic electrophyisiological mapping of VP GABAergic neurons in the adult rat brain. We show that the more medial levels of the rostral subcommissural VP contain neurons that have electrophysiological, morphological, and synaptic input characteristics distinct from other neurons in the rest of the VP. Specifically, in spite of their presence in the region staining densely for enkephalin immunoreactivity the type 2 neurons in the rostral VP in the medial slice, including but not restricted to the VPdl, resemble spiny neurons in the adjacent NAshell and IPAC, and may thus function more as part of the extended amygdala or NAshell (Alheid 2003; Heimer et al. $1997 \mathrm{a}, \mathrm{b}$ ). These data complement and extend the general idea of transitional areas around the boundaries between regions in the basal forebrain that was developed using anatomical and morphological methods (Alheid 2003; Heimer et al. 1997b), and supply electrophysiological evidence indicating mixture of striatal and pallidal neurons in the rostral subcommissural VP. Such findings may provide us with better explanations for behavioral differences found between the rostral and caudal VP in previous studies, and will aid future behavioral and particularly electrophysiological experiments in investigating the different subregions of the VP. 


\section{Acknowledgments}

We would like to thank Rachel Smith for assistance with enkephalin immunostaining. This work was supported by USPHA grants DA015369, DA012513, DA003906, and by the Neuroscience Institute, Medical University of South Carolina.

\section{References}

Alheid GF. Extended amygdala and basal forebrain. Ann N Y Acad Sci. 2003; 985:185-205. [PubMed: 12724159]

Alheid GF, Heimer L. New perspectives in basal forebrain organization of special relevance for neuropsychiatric disorders: the striatopallidal, amygdaloid, and corticopetal components of substantia innominata. Neuroscience. 1988; 27(1):1-39. [PubMed: 3059226]

Bell K, Churchill L, Kalivas PW. GABAergic projection from the ventral pallidum and globus pallidus to the subthalamic nucleus. Synapse. 1995; 20(1):10-18.10.1002/syn.890200103 [PubMed: 7624824]

Bengtson CP, Osborne PB. Electrophysiological properties of anatomically identified ventral pallidal neurons in rat brain slices. Ann N Y Acad Sci. 1999; 877:691-694. [PubMed: 10415685]

Bengtson CP, Osborne PB. Electrophysiological properties of cholinergic and noncholinergic neurons in the ventral pallidal region of the nucleus basalis in rat brain slices. J Neurophysiol. 2000; 83(5): 2649-2660. [PubMed: 10805665]

Bengtson CP, Lee DJ, Osborne PB. Opposing electrophysiological actions of 5-HT on noncholinergic and cholinergic neurons in the rat ventral pallidum in vitro. J Neurophysiol. 2004; 92(1):433443.10.1152/jn.00543.2003 [PubMed: 14960557]

Churchill L, Kalivas PW. A topographically organized gamma-aminobutyric acid projection from the ventral pallidum to the nucleus accumbens in the rat. J Comp Neurol. 1994; 345(4):579_ 595.10.1002/cne.903450408 [PubMed: 7962701]

Cromwell HC, Berridge KC. Where does damage lead to enhanced food aversion: the ventral pallidum/substantia innominata or lateral hypothalamus? Brain Res. 1993; 624(1-2):1-10. [PubMed: 8252379]

Fabbricatore AT, Ghitza UE, Prokopenko VF, West MO. Electrophysiological evidence of mediolateral functional dichotomy in the rat nucleus accumbens during cocaine self-administration II: phasic firing patterns. Eur J Neurosci. 2010; 31(9):1671-1682.10.1111/j. 1460-9568.2010.07230.x [PubMed: 20525080]

Forcelli PA, West EA, Murnen AT, Malkova L. Ventral pallidum mediates amygdala-evoked deficits in prepulse inhibition. Behav Neurosci. 2012; 126(2):290-300.10.1037/a0026898 [PubMed: 22250771]

Fuller TA, Russchen FT, Price JL. Sources of presumptive glutamergic/aspartergic afferents to the rat ventral striatopallidal region. J Comp Neurol. 1987; 258(3):317-338.10.1002/cne.902580302 [PubMed: 2884240]

Gartner U, Hartig W, Riedel A, Brauer K, Arendt T. Immunocytochemical evidence for the striatal nature of the rat lateral part of interstitial nucleus of the posterior limb of the anterior commissure (IPAC). J Chem Neuroanat. 2002; 24(2):117-125. [PubMed: 12191728]

Gritti I, Mainville L, Jones BE. Codistribution of GABA—with acetylcholine-synthesizing neurons in the basal forebrain of the rat. J Comp Neurol. 1993; 329(4):438-457.10.1002/cne.903290403 [PubMed: 8454735]

Groenewegen HJ, Berendse HW, Wolters JG, Lohman AH. The anatomical relationship of the prefrontal cortex with the striatopallidal system, the thalamus and the amygdala: evidence for a parallel organization. Prog Brain Res. 1990; 85:95-116. discussion 116-118. [PubMed: 2094917]

Groenewegen HJ, Berendse HW, Haber SN. Organization of the output of the ventral striatopallidal system in the rat: ventral pallidal efferents. Neuroscience. 1993; 57(1):113-142. [PubMed: 8278047]

Haber SN, Nauta WJ. Ramifications of the globus pallidus in the rat as indicated by patterns of immunohistochemistry. Neuroscience. 1983; 9(2):245-260. [PubMed: 6192358] 
Hanlon EC, Baldo BA, Sadeghian K, Kelley AE. Increases in food intake or food-seeking behavior induced by GABAergic, opioid, or dopaminergic stimulation of the nucleus accumbens: is it hunger? Psychopharmacology. 2004; 172(3):241-247.10.1007/s00213-003-1654-0 [PubMed: 14598017]

Heimer, L.; Wilson, RD. The subcortical projections of the allocortex: similarities in the neural associations of the hippocampus, the piriform cortex, and the neocortex. In: Santini, M., editor. Golgi centennial symposium proceedings. Raven Press; New York: 1975. p. 177-193.

Heimer L, Zahm DS, Churchill L, Kalivas PW, Wohltmann C. Specificity in the projection patterns of accumbal core and shell in the rat. Neuroscience. 1991; 41(1):89-125. [PubMed: 2057066]

Heimer L, Alheid GF, de Olmos JS, Groenewegen HJ, Haber SN, Harlan RE, Zahm DS. The accumbens: beyond the core-shell dichotomy. J Neuropsychiatry Clin Neurosci. 1997a; 9(3):354381. [PubMed: 9276840]

Heimer L, Harlan RE, Alheid GF, Garcia MM, de Olmos J. Substantia innominata: a notion which impedes clinical-anatomical correlations in neuropsychiatric disorders. Neuroscience. 1997b; 76(4):957-1006. [PubMed: 9027863]

Hiroi N, White NM. The ventral pallidum area is involved in the acquisition but not expression of the amphetamine conditioned place preference. Neurosci Lett. 1993; 156(1-2):9-12. [PubMed: 8414197]

Holt AG, Newman SW. Distribution of methionine and leucine enkephalin neurons within the social behavior circuitry of the male Syrian hamster brain. Brain Res. 2004; 1030(1):28-48.10.1016/ j.brainres.2004.09.034 [PubMed: 15567335]

Hubner CB, Koob GF. The ventral pallidum plays a role in mediating cocaine and heroin selfadministration in the rat. Brain Res. 1990; 508(1):20-29. [PubMed: 2337788]

Johnson PI, Napier TC. Contribution of the nucleus accumbens to cocaine-induced responses of ventral pallidal neurons. Synapse. 1996; 22(3):253-260.10.1002/ (SICI)1098-2396(199603)22:3<253:AID-SYN8>3.0.CO;2-B [PubMed: 9132994]

Kalivas PW, Jackson D, Romanidies A, Wyndham L, Duffy P. Involvement of pallidothalamic circuitry in working memory. Neuroscience. 2001; 104(1):129-136. [PubMed: 11311537]

Kelley AE, Domesick VB, Nauta WJ. The amygdalostriatal projection in the rat-an anatomical study by anterograde and retrograde tracing methods. Neuroscience. 1982; 7(3):615-630. [PubMed: 7070669]

Kodsi MH, Swerdlow NR. Regulation of prepulse inhibition by ventral pallidal projections. Brain Res Bull. 1997; 43(2):219-228. [PubMed: 9222535]

Koester, J.; Siegelbaum, SA. Local signaling: passive electrical properties of the neuron. In: Kandel, ER.; Schwartz, JH.; Jessell, TM., editors. Principles of neural science. 4. McGraw-Hill; New York: 2000.

Lavin A, Grace AA. Physiological properties of rat ventral pallidal neurons recorded intracellularly in vivo. J Neurophysiol. 1996; 75(4):1432-1443. [PubMed: 8727388]

Maidment NT, Brumbaugh DR, Rudolph VD, Erdelyi E, Evans CJ. Microdialysis of extracellular endogenous opioid peptides from rat brain in vivo. Neuroscience. 1989; 33(3):549-557. [PubMed: 2636708]

Martin TJ, Coller M, Co C, Smith JE. Mu-opioid receptor alkylation in the ventral pallidum and ventral tegmental area, but not in the nucleus accumbens, attenuates the effects of heroin on cocaine self-administration in rats. Neuropsychopharmacology. 2008; 33(5):1171-1178.10.1038/ sj.npp.1301490 [PubMed: 17581528]

Maurice N, Deniau JM, Menetrey A, Glowinski J, Thierry AM. Position of the ventral pallidum in the rat prefrontal cortex-basal ganglia circuit. Neuroscience. 1997; 80(2):523-534. [PubMed: 9284354]

McFarland K, Kalivas PW. The circuitry mediating cocaine-induced reinstatement of drug-seeking behavior. J Neurosci. 2001; 21(21):8655-8663. [PubMed: 11606653]

Mitrovic I, Napier TC. Electrophysiological demonstration of mu, delta and kappa opioid receptors in the ventral pallidum. J Pharmacol Exp Ther. 1995; 272(3):1260-1270. [PubMed: 7891342]

Mogenson GJ, Yang CR. The contribution of basal forebrain to limbic-motor integration and the mediation of motivation to action. Adv Exp Med Biol. 1991; 295:267-290. [PubMed: 1776572] 
Mogenson GJ, Jones DL, Yim CY. From motivation to action: functional interface between the limbic system and the motor system. Prog Neurobiol. 1980; 14(2-3):69-97. [PubMed: 6999537]

Nambu A, Llinas R. Morphology of globus pallidus neurons: its correlation with electrophysiology in guinea pig brain slices. J Comp Neurol. 1997; 377(1):85-94. [PubMed: 8986874]

Napier, TC. Transmitter actions and interactions on pallidal neuronal function. In: Kalivas, PW.; Barnes, CD., editors. Limbic motor circuits and neuropsychiatry. CRC Press; Boca Raton: 1993. p. 125-153.

Napier TC, Mitrovic I. Opioid modulation of ventral pallidal inputs. Ann N Y Acad Sci. 1999; 877:176-201. [PubMed: 10415650]

O'Donnell P, Grace AA. Physiological and morphological properties of accumbens core and shell neurons recorded in vitro. Synapse. 1993; 13(2):135-160.10.1002/syn.890130206 [PubMed: 8446922]

Olive MF, Anton B, Micevych P, Evans CJ, Maidment NT. Presynaptic versus postsynaptic localization of $\mathrm{mu}$ and delta opioid receptors in dorsal and ventral striatopallidal pathways. $\mathrm{J}$ Neurosci. 1997; 17(19):7471-7479. [PubMed: 9295393]

Panagis G, Miliaressis E, Anagnostakis Y, Spyraki C. Ventral pallidum self-stimulation: a moveable electrode mapping study. Behav Brain Res. 1995; 68(2):165-172. [PubMed: 7654303]

Pang K, Tepper JM, Zaborszky L. Morphological and electrophysiological characteristics of noncholinergic basal forebrain neurons. J Comp Neurol. 1998; 394(2):186-204. [PubMed: 9552125]

Paxinos, G.; Watson, C. The Rat Brain in Stereotaxic Coordinates. 6. Academic Press; San Diego: 2006.

Pecina S, Berridge KC. Hedonic hot spot in nucleus accumbens shell: where do mu-opioids cause increased hedonic impact of sweetness? J Neurosci. 2005; 25(50):11777-11786.10.1523/ JNEUROSCI.2329-05.2005 [PubMed: 16354936]

Pickel VM, Shobin ET, Lane DA, Mackie K. Cannabinoid-1 receptors in the mouse ventral pallidum are targeted to axonal profiles expressing functionally opposed opioid peptides and contacting Nacylphosphatidylethanolamine-hydrolyzing phospholipase D terminals. Neuroscience. 2012; 227C:10-21.10.1016/j.neuroscience.2012.07.050 [PubMed: 22863674]

Robledo P, Koob GF. Two discrete nucleus accumbens projection areas differentially mediate cocaine self-administration in the rat. Behav Brain Res. 1993; 55(2):159-166. [PubMed: 8395179]

Root DH, Fabbricatore AT, Ma S, Barker DJ, West MO. Rapid phasic activity of ventral pallidal neurons during cocaine self-administration. Synapse. 2010; 64(9):704-713.10.1002/syn.20792 [PubMed: 20340176]

Root DH, Fabbricatore AT, Pawlak AP, Barker DJ, Ma S, West MO. Slow phasic and tonic activity of ventral pallidal neurons during cocaine self-administration. Synapse. 2012a; 66(2):106127.10.1002/syn.20990 [PubMed: 21953543]

Root DH, Ma S, Barker DJ, Megehee L, Striano BM, Ralston CM, Fabbricatore AT, West MO. Differential roles of ventral pallidum subregions during cocaine self-administration behaviors. J Comp Neurol. 2012b10.1002/cne.23191

Shammah-Lagnado SJ, Alheid GF, Heimer L. Afferent connections of the interstitial nucleus of the posterior limb of the anterior commissure and adjacent amygdalostriatal transition area in the rat. Neuroscience. 1999; 94(4):1097-1123. [PubMed: 10625051]

Shammah-Lagnado SJ, Alheid GF, Heimer L. Striatal and central extended amygdala parts of the interstitial nucleus of the posterior limb of the anterior commissure: evidence from tract-tracing techniques in the rat. J Comp Neurol. 2001; 439(1):104-126.10.1002/cne.1999 [PubMed: 11584811]

Skoubis PD, Maidment NT. Blockade of ventral pallidal opioid receptors induces a conditioned place aversion and attenuates acquisition of cocaine place preference in the rat. Neuroscience. 2003; 119(1):241-249. [PubMed: 12763085]

Smith KS, Berridge KC. The ventral pallidum and hedonic reward: neurochemical maps of sucrose "liking" and food intake. J Neurosci. 2005; 25(38):8637-8649.10.1523/JNEUROSCI. 1902-05.2005 [PubMed: 16177031] 
Smith KS, Tindell AJ, Aldridge JW, Berridge KC. Ventral pallidum roles in reward and motivation. Behav Brain Res. 2009; 196(2):155-167.10.1016/j.bbr.2008.09.038 [PubMed: 18955088]

Switzer RC 3rd, Hill J, Heimer L. The globus pallidus and its rostroventral extension into the olfactory tubercle of the rat: a cyto- and chemoarchitectural study. Neuroscience. 1982; 7(8):1891-1904. [PubMed: 7133405]

Taha SA, Katsuura Y, Noorvash D, Seroussi A, Fields HL. Convergent, not serial, striatal and pallidal circuits regulate opioid-induced food intake. Neuroscience. 2009; 161(3):718-733.10.1016/ j.neuroscience.2009.03.057 [PubMed: 19336249]

Tang XC, McFarland K, Cagle S, Kalivas PW. Cocaine-induced reinstatement requires endogenous stimulation of mu-opioid receptors in the ventral pallidum. J Neurosci. 2005; 25(18):45124520.10.1523/JNEUROSCI.0685-05.2005 [PubMed: 15872098]

Tindell AJ, Smith KS, Pecina S, Berridge KC, Aldridge JW. Ventral pallidum firing codes hedonic reward: when a bad taste turns good. J Neurophysiol. 2006; 96(5):2399-2409.10.1152/jn. 00576.2006 [PubMed: 16885520]

Tripathi A, Prensa L, Cebrian C, Mengual E. Axonal branching patterns of nucleus accumbens neurons in the rat. J Comp Neurol. 2010; 518(22):4649-4673.10.1002/cne.22484 [PubMed: 20886627]

Wilson FA, Rolls ET. Neuronal responses related to reinforcement in the primate basal forebrain. Brain Res. 1990; 509(2):213-231. [PubMed: 2322819]

Yin HH, Knowlton BJ. The role of the basal ganglia in habit formation. Nat Rev Neurosci. 2006; 7(6): 464-476.10.1038/nrn1919 [PubMed: 16715055]

Zahm DS. The ventral striatopallidal parts of the basal ganglia in the rat-II. Compartmentation of ventral pallidal efferents. Neuroscience. 1989; 30(1):33-50. [PubMed: 2473414]

Zahm DS. Is the caudomedial shell of the nucleus accumbens part of the extended amygdala? A consideration of connections. Crit Rev Neurobiol. 1998; 12(3):245-265. [PubMed: 9847057]

Zahm DS, Heimer L. Ventral striatopallidal parts of the basal ganglia in the rat: I. Neurochemical compartmentation as reflected by the distributions of neurotensin and substance $\mathrm{P}$ immunoreactivity. J Comp Neurol. 1988; 272(4):516-535.10.1002/cne.902720406 [PubMed: 2458391]

Zahm DS, Heimer L. Two transpallidal pathways originating in the rat nucleus accumbens. J Comp Neurol. 1990; 302(3):437-446.10.1002/cne.903020302 [PubMed: 1702109]

Zahm DS, Zaborszky L, Alones VE, Heimer L. Evidence for the coexistence of glutamate decarboxylase and Met-enkephalin immunoreactivities in axon terminals of rat ventral pallidum. Brain Res. 1985; 325(1-2):317-321. [PubMed: 3884089]

Zahm DS, Williams E, Wohltmann C. Ventral striatopallido-thalamic projection: IV. Relative involvements of neurochemically distinct subterritories in the ventral pallidum and adjacent parts of the rostroventral forebrain. J Comp Neurol. 1996; 364(2):340-362.10.1002/ (SICI)1096-9861(19960108)364:2<340: :AID-CNE11>3.0.CO;2-T [PubMed: 8788254]

Zahm DS, Parsley KP, Schwartz ZM, Cheng AY. On lateral septum-like characteristics of outputs from the accumbal hedonic 'hotspot' of Pecina and Berridge with commentary on the transitional nature of basal forebrain 'boundaries'. J Comp Neurol. 201210.1002/cne.23157

Zarrindast MR, Ebrahimi-Ghiri M, Rostami P, Rezayof A. Repeated pre-exposure to morphine into the ventral pallidum enhances morphine-induced place preference: involvement of dopaminergic and opioidergic mechanisms. Behav Brain Res. 2007; 181(1):35-41.10.1016/j.bbr.2007.03.019 [PubMed: 17451818]

Zhang M, Kelley AE. Opiate agonists microinjected into the nucleus accumbens enhance sucrose drinking in rats. Psychopharmacology. 1997; 132(4):350-360. [PubMed: 9298512]

Zhang M, Kelley AE. Enhanced intake of high-fat food following striatal mu-opioid stimulation: microinjection mapping and fos expression. Neuroscience. 2000; 99(2):267-277. [PubMed: 10938432] 

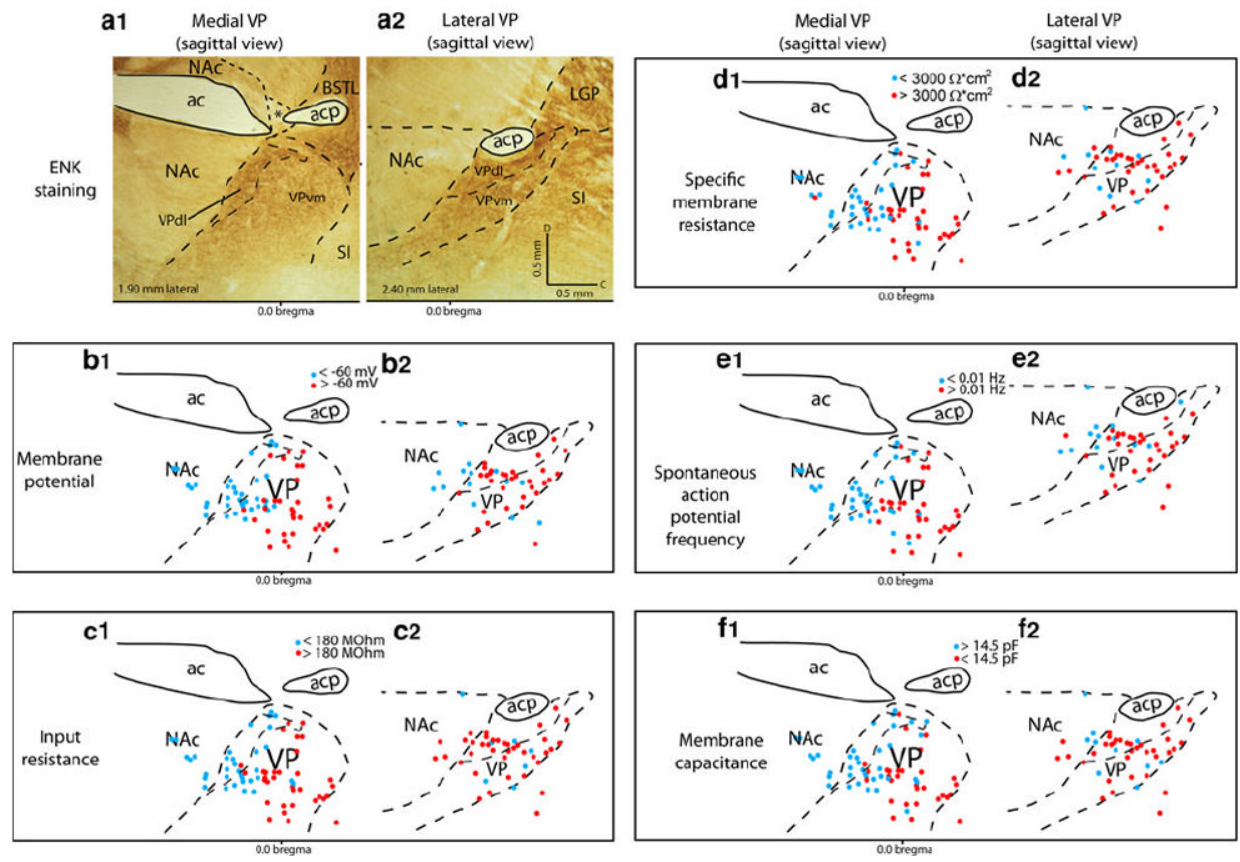

Fig. 1.

Electrophysiological maps of medial and lateral VP slices. a Micrographs of medial $\left(a_{1}\right)$ and lateral $\left(a_{2}\right)$ sagittal slices of the VP. Immunoreactive met-enkephalin (ENK) delineates the classic borders of the VP, as indicated by the dashed lines. $\mathbf{b}-\mathbf{f}$ Distribution of cells patched in and around the medial $\left(b_{1}, c_{1}, d_{1}, e_{1}, f_{1}\right)$ and lateral $\left(b_{2}, c_{2}, d_{2}, e_{2}, f_{2}\right) \mathrm{VP}$ according to their membrane potential (b), input resistance $(\mathbf{c})$, specific membrane resistance $(\mathbf{d})$, spontaneous action potential frequency (e), and membrane capacitance (f). Calibration bars in $a_{2}$ correspond to all panels. Slices are positioned such that the caudal side (denoted "C" on calibration bars) faces the right and the dorsal side (denoted " $\mathrm{D}$ " on calibration bars) faces up. ac anterior commissure, acp posterior limb of anterior commissure, BSTL bed nucleus of the stria terminalis, lateral division, $L G P$ globus pallidus, lateral portion, $N A c$ nucleus accumbens, $S I$ substantia innominata, $V P$ ventral pallidum, $V P d l$ dorsolateral VP, $V P V m$ ventromedial VP, asterisk interstitial nucleus of the posterior limb of the anterior commissure (IPAC) 

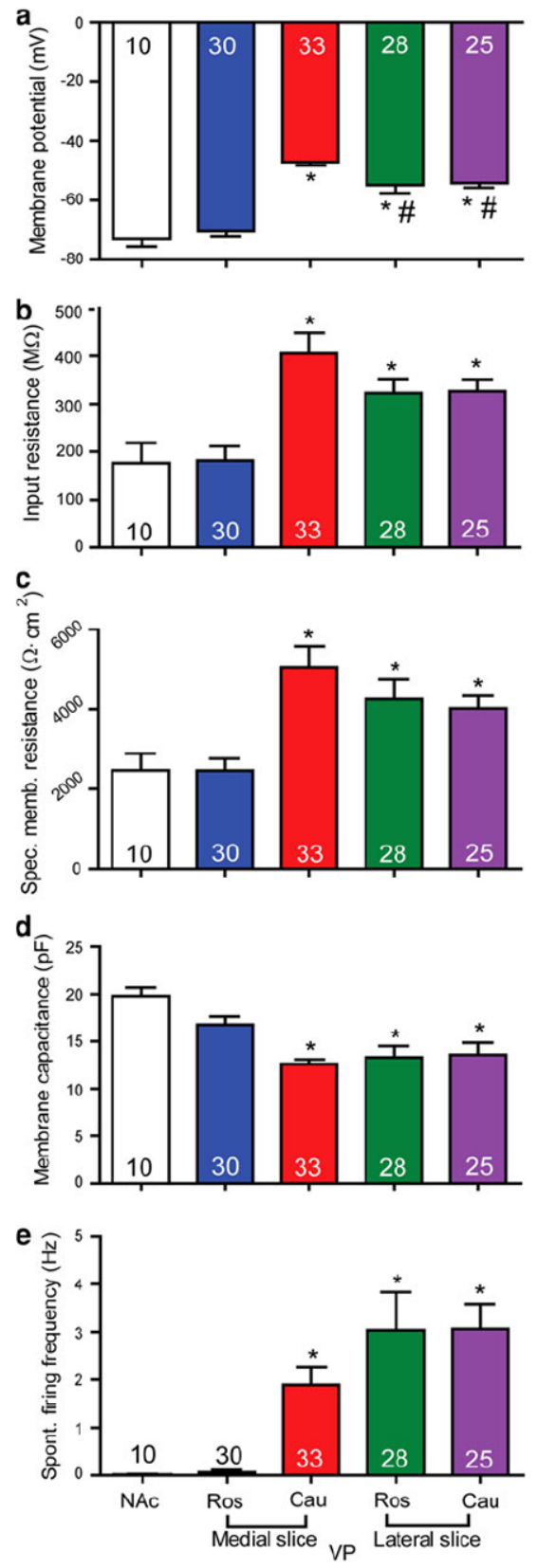

Fig. 2.

Mean electrophysiological characteristics of neurons in the rostral and caudal VP at two mediolateral planes. a-e Mean \pm SEM membrane potential (a), input resistance (b), specific membrane resistance (c), membrane capacitance (d), and frequency of spontaneous action potentials (e) in the nucleus accumbens and the VP. Significance measured with one-way ANOVA. ${ }^{*} p<0.01$ compared to rostral VP in medial slice (blue bar), ${ }^{*} p<0.05$ comparing rostral and caudal VP in lateral slice to caudal VP in medial slice (red bar) using Bonferroni post hoc analysis. Numbers in columns represent number of cells. NAc nucleus accumbens, Ros rostral, Cau caudal 

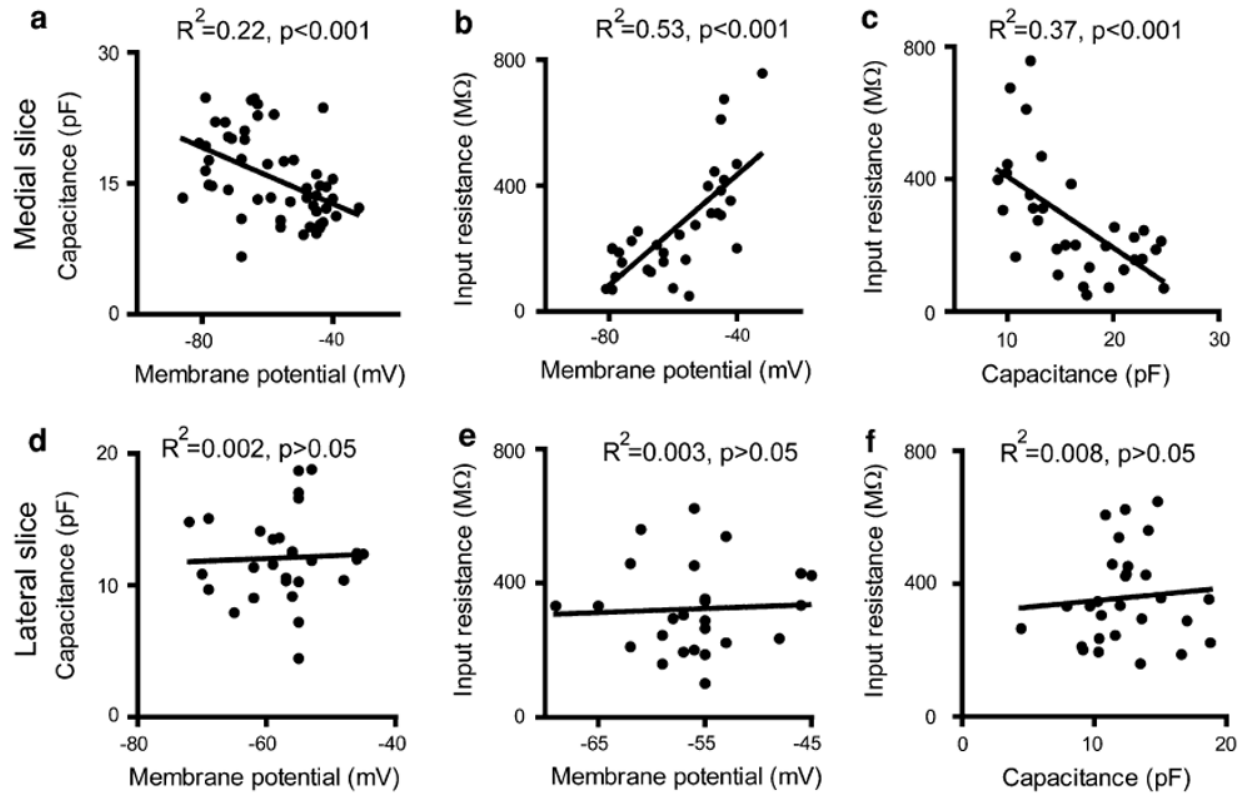

Fig. 3.

Correlations between three electrophysiological measures in neurons of the medial and lateral slices of the VP. a-c In the medial slice of the VP, there was a significant correlation between membrane potential and capacitance (a), membrane potential and input resistance (b), and input resistance and capacitance (c). In the lateral slice of the VP (d-f), there was no correlation between any pair of these measures 


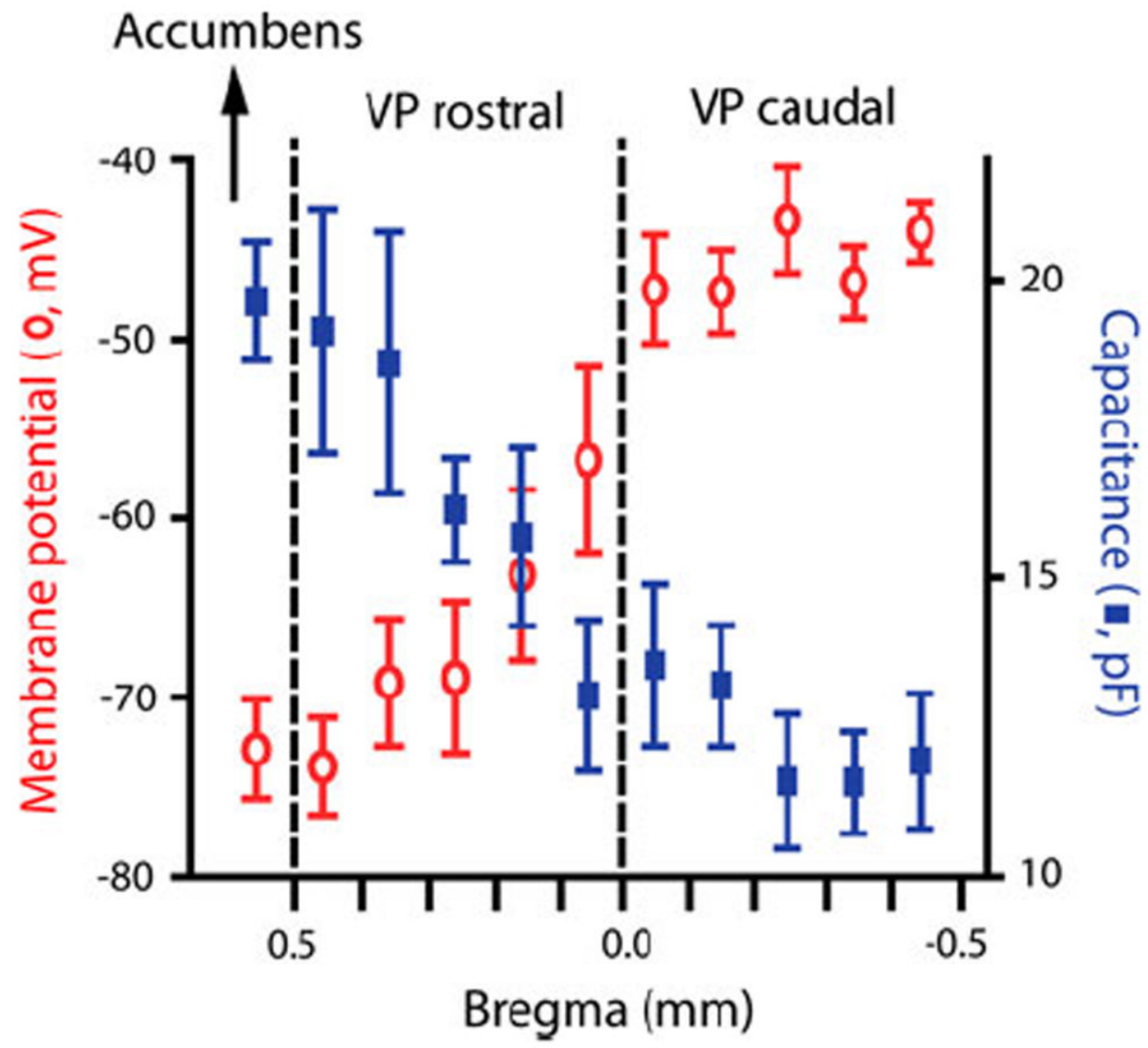

Fig. 4.

The rostral VP in the medial slice contains a gradual change in the proportions of type 1 and type 2 neurons. The changes in the mean \pm SEM membrane potential (open circles) and membrane capacitance (squares) from the caudal part of the nucleus accumbens to the caudal VP are presented on a rostral-caudal axis. The maps in Fig. $1 b_{1}, f_{1}$ were binned into $0.1 \mathrm{~mm}$ columns and each datapoint here represents the average value of all neurons in the same column. Membrane potential gradually changed from $-72.9 \pm 2.8 \mathrm{mV}$ in the accumbens to $-44.0 \pm 1.7 \mathrm{mV}$ in the caudal VP. Membrane capacitance gradually decreased from $19.6 \pm 1 \mathrm{pF}$ in the accumbens to $11.9 \pm 1.1 \mathrm{pF}$ in the caudal VP. The average coefficient of variation was higher in the rostral VP than in the accumbens or the caudal VP for both measures (note bigger error bars in rostral VP), indicating that the rostral VP is a heterogenous transition zone between type 1 and type 2 neurons. Dashed lines represent the border between the VP and the accumbens (left line) and the estimated border between the rostral and caudal VP (right line) 

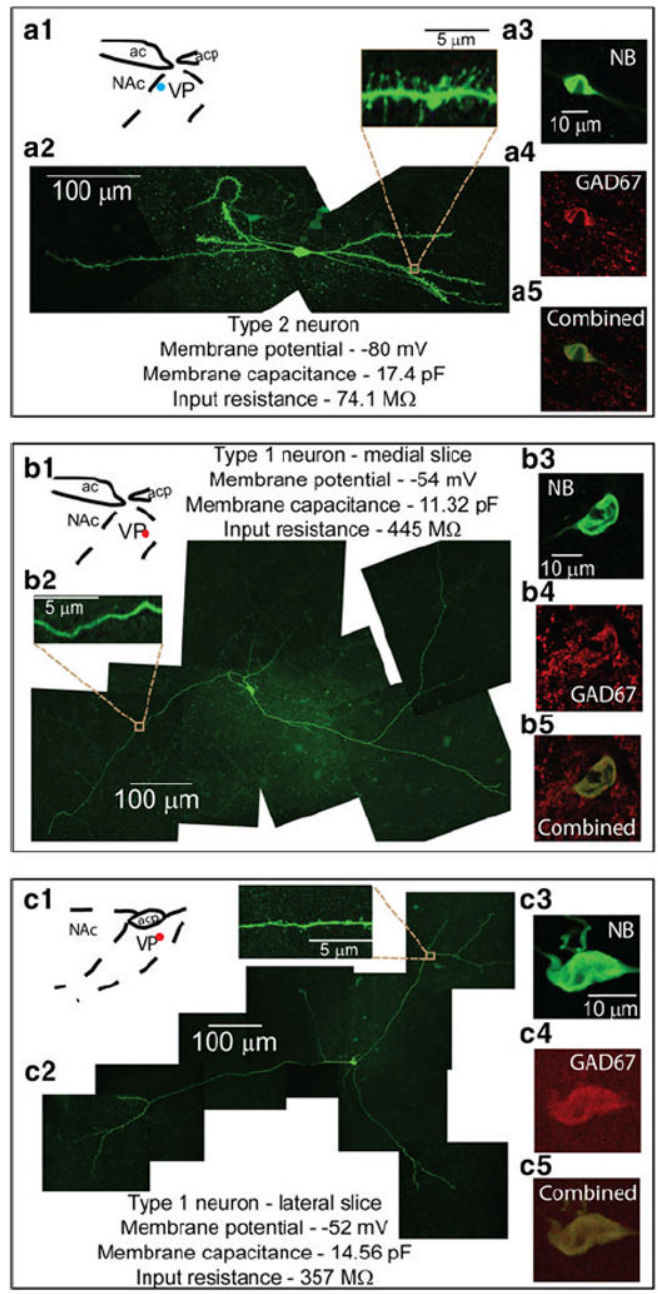

Fig. 5.

Micrographs of neurobiotin-injected neurons in the VP. $a_{1-5}$ A type 2 neuron located in the rostral VP of the medial slice. $a_{1}$ Location of the stained cell in the medial slice map from Fig. $1 a_{1}$. Although this specific neuron was located in the VPdl, other type 2 neurons in the medial slice were located also in the VPvm. $a_{2}$ Micrograph of the immunoreactivity to neurobiotin of the rostral VP neuron. Inset a dendrite segment in higher magnification showing density of spines on the dendrite. $a_{3}$ Immunoreactivity of the soma to neurobiotin. $a_{4}$ Immunoreactivity of the soma to GAD67 (indicating it is a GABAergic neuron). $a_{5}$ Micrographs from $\mathrm{a}_{3}$ and $\mathrm{a}_{4}$ superimposed. The dent in the soma was produced by the patching electrode. $b_{1-5}$ Same as in a but for a type 1 neuron located in the caudal VP of the medial slice. Cells were found both in the VPdl and in the VPvm. $c_{1-5}$ Same as in a but for a type 1 neuron located in the lateral slice of the VP 
Type 2 cell - rostral VP medial slice

Type 1 cell - caudal VP medial slice
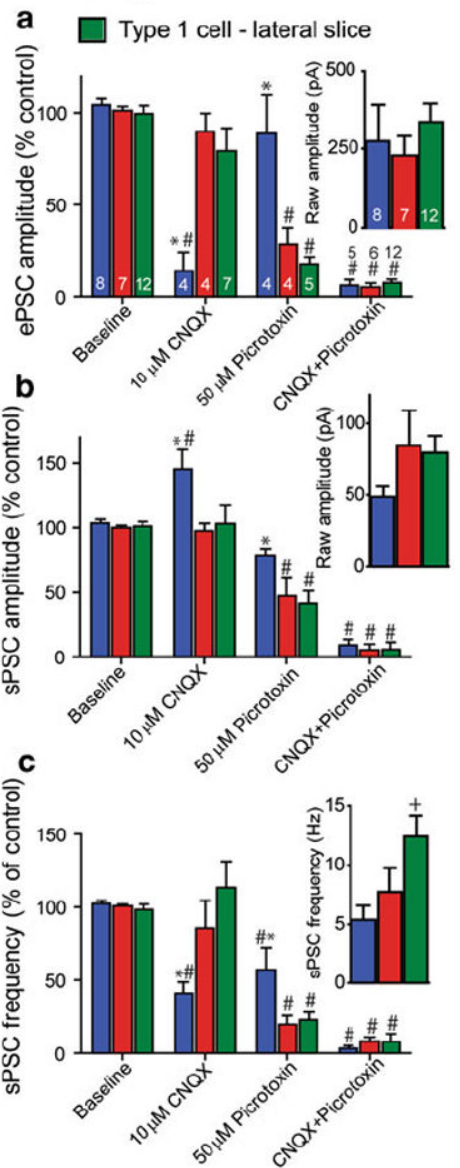

d Type 2 cell - rostral VP medial slice
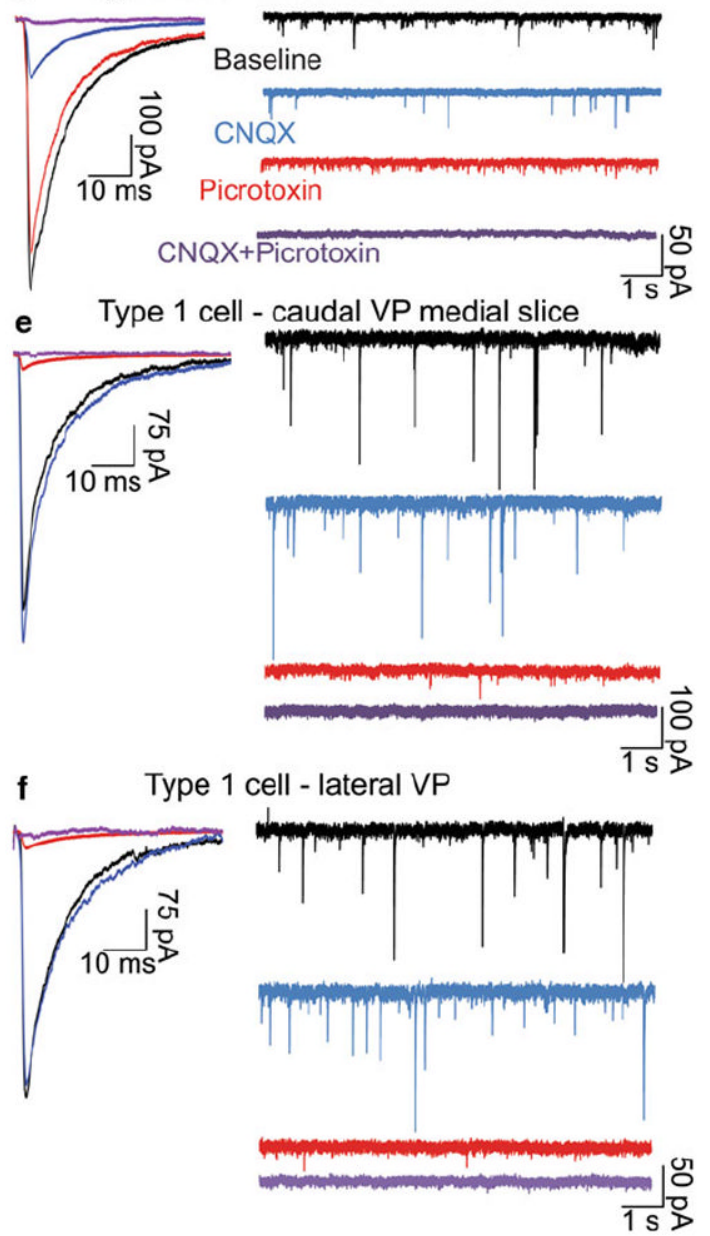

Fig. 6.

The effects of CNQX, an AMPA/kainate receptor blocker, and picrotoxin, a GABA receptor blocker, on evoked (ePSCs) and spontaneous (sPSCs) postsynaptic currents in VP neurons. a The effect of application of either $10 \mu \mathrm{M}$ CNQX or $50 \mu \mathrm{M}$ picrotoxin on the ePSC amplitude depended on the cell type $\left(F_{(6,66)}=14.77, p<0.0001\right.$ for interaction between treatment $\times$ cell type, two-way ANOVA). Application of $10 \mu \mathrm{M} \mathrm{CNQX}$ inhibited the ePSCs in type 2 neurons from the rostral VP but not in type 1 VP neurons. Fifty micromolar picrotoxin inhibited ePSCs in VP type 1 neurons but not in type 2 neurons. Coapplication of both antagonists completely blocked the ePSCs in both types of neuron. Inset the average raw amplitude of the ePSC did not vary between cell types. $\mathbf{b}$ The effect of application of either $10 \mu \mathrm{M}$ CNQX or $50 \mu \mathrm{M}$ picrotoxin on the sPSC amplitude depended on the cell type $\left(F_{(6,66)}=2.75, p<0.05\right.$ for interaction between treatment $\times$ cell type, two-way ANOVA). Application of $10 \mu \mathrm{M}$ CNQX increased the average amplitude of the sPSCs in VP type 2 neurons but not VP type 1 neurons. Fifty micromolar picrotoxin inhibited the amplitude of the sPSCs in VP type 1 neurons but not in type 2 neurons. Co-application of both antagonists completely inhibited the sPSCs in both cell types. Inset the average raw amplitude of the sPSC did not vary between cell types. $\mathbf{c}$ The effect of application of either $10 \mu \mathrm{M} C N Q X$ or $50 \mu \mathrm{M}$ picrotoxin on the sPSC frequency depended on the cell type $\left(F_{(6,66)}\right.$ $=6.27, p<0.0001$ for interaction between treatment $\times$ cell type, two-way ANOVA).

Application of $10 \mu \mathrm{M} \mathrm{CNQX}$ decreased the frequency of sPSCs in type 2 neurons but not in 
type 1 neurons. Fifty micromolar picrotoxin decreased the frequency of sPSCs in all VP neurons. Co-application of both antagonists completely blocked spontaneous activity in all VP cell types. Inset the average raw frequency of sPSCs was higher in type 1 VP neurons from the lateral slice than in type 2 VP neurons from the medial slice, but no differences were found between type 1 and 2 neurons in the medial slice or between type 1 neurons in the lateral and medial slices. d-f Representative traces of ePSCs (left) and SPSCs (right) in type 2 (d), type 1 (medial slice) (e), and type 1 (lateral slice) (f) VP neurons for all experimental conditions. ${ }^{\#} p<0.01$ each column compared to its control using Bonferroni post hoc analysis. ${ }^{*} p<0.01$ each column compared to the type 1 caudal VP (lateral slice) column (the middle column in each group) within the same treatment using Bonferroni post hoc analysis. ${ }^{+} p<0.01$ compared to type 2 neurons using Bonferroni post hoc analysis.

Numbers in or above column indicate number of cells 
